
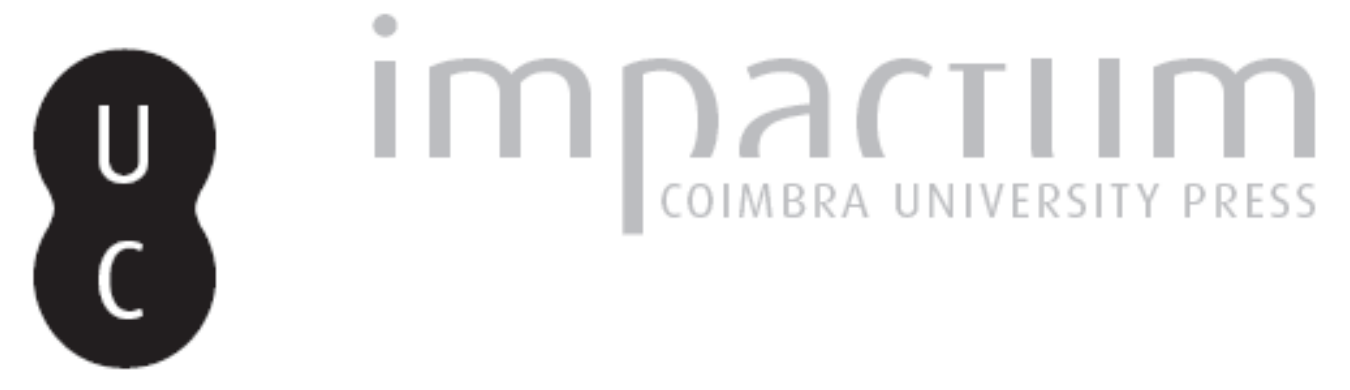

\title{
[Recensão a] La Collezione Epigrafica dei Musei Capitolini
}

\author{
Autor(es): D'Encarnação, José
}

Publicado por: Imprensa da Universidade de Coimbra

URL persistente:

URI:http://hdl.handle.net/10316.2/45556

DOI:

DOI:https://dx.doi.org/10.14195/1647-8657_29_14

Accessed : $\quad$ 26-Apr-2023 11:35:24

A navegação consulta e descarregamento dos títulos inseridos nas Bibliotecas Digitais UC Digitalis, UC Pombalina e UC Impactum, pressupõem a aceitação plena e sem reservas dos Termos e Condições de Uso destas Bibliotecas Digitais, disponíveis em https://digitalis.uc.pt/pt-pt/termos.

Conforme exposto nos referidos Termos e Condições de Uso, o descarregamento de títulos de acesso restrito requer uma licença válida de autorização devendo o utilizador aceder ao(s) documento(s) a partir de um endereço de IP da instituição detentora da supramencionada licença.

Ao utilizador é apenas permitido o descarregamento para uso pessoal, pelo que o emprego do(s) título(s) descarregado(s) para outro fim, designadamente comercial, carece de autorização do respetivo autor ou editor da obra.

Na medida em que todas as obras da UC Digitalis se encontram protegidas pelo Código do Direito de Autor e Direitos Conexos e demais legislação aplicável, toda a cópia, parcial ou total, deste documento, nos casos em que é legalmente admitida, deverá conter ou fazer-se acompanhar por este aviso.

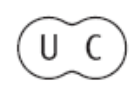


FACULDADE DE LETRAS

INSTITUTO DE ARQUEOLOGIA

CONIMBRIGA

VOLUME XXIX

UNIVERSIDADE DE COIMBRA

1990 
T. Peticius Hispanus (pp. 187-188). O referido movimento migratorio obtém, desta sorte, mais um argumento abonatório.

Em suma: pela densidade e rigor da informação que transmite, este volume constitui, acima de tudo, a demonstração cabal do incansável e permanente labor de revisão do (quase) inesgotável espólio epigráfico itálico, a que uma briosa equipa de investigadores, dirigidos por Margherita Guarducci e Silvio Panciera em boa hora souberam lançar ombros.

JOSÉ D'ENCARNAÇAO

La Collezione Epigrafica dei Musei Capitolini, Edizioni di Storia e Letterature, Roma, 1987, 392 pp. + LXXVIII de lâminas com fotos.

Incluído, com o n. ${ }^{\circ}$ 6, na colecção Tituli (Pubblicazioni di Epigrafia e Antichità Greche e Romane dell'Università di Roma — La Sapienza), este volume foi organizado sob orientação do Prof. Silvio Panciera, responsável, desde há vários anos, pelo Seminário de Epigrafia e Antiguidades Romanas na referida universidade. O volume resulta, pois, do persistente trabalho de estudo e revisão de monumentos epigráficos aí levado a efeito.

Publicam-se, na primeira parte (pp. 29-263), como Silvio Panciera, aliás, explicita na introdução, todas as inscrições latinas e gregas identificadas no conjunto dos museus Capitolinos (ou seja, o Museu Capitolino propriamente dito, o Palácio dos Conservadores, o chamado Braccio Nuovo, o Museu Novo, a Galeria Lapidar de Congiunzione e o Tabularium) que estavam inéditas até 1985 , num total de 183.

Dá-se conta, na segunda parte (pp. 265-330), das revisões de epígrafes já conhecidas e que uma melhor fotografia ou a observação mais aturada agora vieram permitir.

A identificação de fragmentos da mesma peça em locais diversos e a possibilidade da sua colagem determinou que, durante a pesquisa, se fossem tomando apontamentos de índole museográfica com vista a mais adequada e racional exposição das peças. Daí a razão de ser da terceira parte, "contributos para a reordenação". E foi dentro dessa mesma ordem de ideias que se elaborou, inclusive, uma tabela de equivalências entre os números do antigo catálogo e do novo. Esta preocupação de atingir os objectivos científicos sem, no entanto, descurar as perspectivas museográficas é, em meu entender, um dos pontos dignos de apreço no volume.

Tomam-no operacional exaustivos índices analíticos: de fontes literárias e epigráficas (pp. 349-375); topográfico (pp. 377-378); epigráficos, segundo o modelo do CIL (pp. 379-389); dos 48 colaboradores do volume (pp. 391-392). As 78 estampas com um total de 345 fotografias, em papel "couché", de muito boa qualidade, facilmente cotejáveis com o catálogo porque vão identificadas mediante a numeração correspondente, constituem, por fim, um repositório ímpar de dados paleográficos e, sobretudo, de tipologías, precisamente porque se adoptou o critério (invulgar, mas precioso) de as arrumar consoante os vários tipos de suporte.

A bibliografia antecede o texto propriamente dito. Aí afigura-se-me desnecessário fazer preceder de AA. VV. ("autores vários") os volumes colectivos, como é o caso das Mélanges ou das actas de colóquios temáticos. A ordenação pelo título seria, decerto, mais fácil e clara.

Conimbriga, 29 (1990), 147-194 
As inscrições inéditas estão arrumadas pela ordem tradicional: votivas, imperiais, honoríficas, funerárias..., com o que particularmente concordamos. É sempre possível agrupar, depois, as epígrafes da mesma proveniência através da consulta dos índices geográficos e, por outro lado, quantas vezes se não desconhece a exacta proveniência da peça guardada no museu!... Terminam a série os fragmentos, os textos cristãos anteriores ao séc. VII e as inscrições falsas.

O capítulo das revisões foi ordenado segundo os corpora. Na terceira parte, as anotações agruparam-se por museus.

De cada inscrição é apresentado um pequeno estudo — uma ficha, diríamos — assinada pelo colaborador dele responsável, que contém: descrição sumária, indicação de proveniência e paradeiro, identificação do negativo fotográfico e do número da respectiva ilustração no volume. Na leitura, em letras minúsculas e de acordo com as Unhas do texto original, utilizam-se os sinais diacríticos preconizados para as novas edições do CIL. O comentário paleogràfico debruça-se sobre as particularidades da paginação e da grafia dos caracteres. O comentário histórico, em geral bastante meticuloso, realça o interesse documental do monumento, em todos os seus aspectos, e propõe, no final, uma datação fundamentada. São aduzidos amiúde exemplos retirados doutros corpora e, se algo houvesse a apontar, seria precisamente a notória ausência, na bibUografia, de textos alusivos à Península Ibérica, sintoma de que a informação ainda não circulou, então, com a eficiência que seria desejável.

É, por conseguinte, um trabalho modelar, com cuja organização concordo inteiramente. A sua consulta, mormente como termo de comparação - a fazer - com a forma e o conteúdo das epígrafes da Península Ibérica revela-se da maior oportunidade.

Aduza-se, a título de exemplo, a ocorrência da fórmula te rogo praeteriens dicas, patente na inscrição 46 (pp. 116-117), a propósito da qual Maria Letizia Caldelli refere os casos hispânicos. Na última parte trata-se, efectivamente, de textos do CIL II e não do CIL VI, como, por gralha tipográfica, foi escrito - o que acabou por induzir em erro quem elaborou os índices de fontes (pp. 352 e seguintes). Uma leitura atenta dos índices do CIL II (pp. 1173 e 1178) ou das Inscripciones Latinas de la Espana Romana, de José Vives (Barcelona, 1971 e 1972), pp. 364-367 (n. os 3761-3787), ter-lhe-ia dado uma noção mais exacta da utilização desta fórmula (CIL II 5241 traz também die rogo qui transis...), proporcionando-lhe, inclusive, outros elementos de datação. Na verdade, afirma Maria Letizia Caldelli que, "das inscrições africanas e hispânicas, só CIL II 5907 é datável: Hübner atribui-o ao século II d. C."-ora, dispomos hoje de critérios que nos possibilitam a datação de boa parte dos demais textos. Os n. ${ }^{\text {ss }} 36$ e 46 do volume II das Fouilles de Conimbriga (Paris, 1976), por exemplo, que trazem esse formulário, são datados dos finais do século II - princípios do III da nossa era.

Uma das outras vezes em que se aduz uma epígrafe peninsular é, na p. 36, a propósito da forma posuuit, que encontraria paralelo em CIL II 2722. O texto, dado o seu carácter fragmentário, não foi recolhido por José Vives, mas Luís Sagredo San Eustaquio e Santos Crespo Ortiz de Zarate incluem-no, sob o n. ${ }^{\circ} 64$ (p. 57) Epigrafia Romana de la Provinda de Palencia (Palencia, 1978) e essa "anomalia" não é ali considerada: posuit surge grafado na obra apenas com um $u$. Em contrapartida, nos índices do CIL II (p. 1190) registam-se outros casos de uso de "uu pro u", designadamente no genitivo da quarta declinação.

A propósito da ocorrência do cognome Doles (inscrição n. ${ }^{\circ}$ 19, pp. 63-67), de origem tràcia, cita Maryline Parva CIL II 2984, de Calagurris, uma inscrição relativa ao soldado

Conimbriga, 29 (1990), 147-194 
Iulius Longinus Doles, da Ala Tartorum Victrix Civium Romanorum. Trata-se, de facto, duma das raras referencias a trácios na epigrafía da Península Ibérica e Patrick Le Roux \{L'Armée Romaine et l'Organisation des Provinces Ibériques d'Auguste à l'Invasion de 409, Paris, 1982, p. 87 n. 34 e p. 216 n. ${ }^{\circ}$ 157) teve ocasião não só de justificar a presença dessa ala na Península Ibérica, possivelmente desde 68 ao fim do século I, como de confirmar a origem tràcia deste eques. Doles não seria, pois, como à primeira vista poderia parecer, um caso de omissão do $n$ antes de $s$ (cf. CIL II, p. 1189) e dever-se-á ter em atenção esse facto ao repensar CIL II 6, onde propus somente a leitura Teia Dole[ns7] (IRCP 27).

$\mathrm{O}$ uso da pontuação entre consoantes duplas na inscrição 52 (pp. 123-124) é justificado por Anna Illuminati, na sequência de Schulze, como sendo uma forma de, assim, se realçar a exactidão da grafia. Cita-se, a propósito, CIL II 4085, de Tarragona. Já os exemplos que pude colher na epigrafia do conventus Pacensis (IRCP, p. 880) não permitem, porém, essa conclusão: textos há que apresentam interpunctio mas não nas consoantes duplas.

De interesse, ainda, a referência à omissão do $i$ na forma verbal posivit - posiut que se regista no n. ${ }^{\circ} 112$ (pp. 194-195). As autoras consideram ser um "perfeito sincopado" e aduzem outros exemplos, entre os quais CIL II 6302, de Palência. A circunstância de essa epígrafe apresentar tantas anomalias ortográficas levar-nos-ia a pensar, de preferência, num erro quer de omissão quer de troca de letras (posiut por posuit). Assim o julgaria, de facto, se não houvesse tais exemplos.

É, evidentemente, a permanente troca de informações que permite o avanço da Ciência, designadamente duma ciência como a Epigrafia que se alicerça em vasta documentação esparsa por todo um Império. Bons e completos índices constituem, por isso, instrumento de trabalho imprescindível. Daí que o volume ora em apreço deva ser, doravante, ponto de referência obrigatório.

JosÉ DENCARNAÇÃo

Miguel CISNEROS CUNCHILOS, Marmoles Hispanos: Su Empleo en la Espana Romana.

Departamento de Ciencias de la Antigüedad, Universidad de Zaragoza, 1988.

ISBN: 84-600-7010-7. 200 páginas.

A oportunidade da obra de Miguel Cisneros Cunchillos resulta incontestável:

1) porque o estudo da proveniência dos mármores usados na escultura, na arquitectura e na epigrafia faculta preciosas informações no dominio da historia da ocupação romana peninsular;

2) porque, sendo uma síntese da sua dissertação de doutoramento, Marmoles $y$ Otras Rocas Explotadas en la España Romana, defendida nesse mesmo ano (1988) na Universidade de Zaragoza, apresenta com clareza, concisão e arguto poder de análise, toda a problemática que envolve a exploração, comercialização e utilização do mármore durante a Antiguidade Clássica.

Como Manuel Martín-Bueno escreve no prólogo de apresentação do livro, uma investigação sobre o mármore ultrapassa hoje "o âmbito próprio dos estudos sobre técni-

Conimbriga, 29 (1990), 147-194 